\title{
La imagen pública de la ciudad de A Coruña
}

\section{The public image of the city of A Coruña}

\author{
María Ángeles González, Jesús A. Dopico y Diego Campos-Juanatey \\ Universidade da Coruña
}

\begin{abstract}
Resumen
El objetivo de este estudio era conocer la imagen que tienen los habitantes de A Coruña sobre su ciudad. Con este fin, se presentó el cuestionario utilizado por Boira (1992), con algunas modificaciones, a un grupo de 130 estudiantes de la Facultad de Ciencias de la Educación de la ciudad de A Coruña (España). Se confirma el papel central de la Torre de Hércules como elemento simbólico y representativo, la asociación de ésta y del mar y las playas con la idea que la mayoría tiene de la ciudad, y la percepción de las plazas de María Pita y de Pontevedra como corazón de la ciudad y como nodo más importante, respectivamente. La ciudad ha sido descrita por muchos participantes como "una ciudad pequeña con todos los servicios cerca".
\end{abstract}

Palabras clave: Imagen pública, ciudad, habitantes, cuestionario.

\begin{abstract}
This work aimed to study the image of the inhabitants of A Coruña (Spain) in this city. For this purpose, the questionnaire used by Boira (1992), with some modifications, was applied to a group of 130 students from the Faculty of Education at the University of A Coruña (Spain). The results confirm the central role of the Hercules Tower in the image of the city, as a symbolic and representative element, the association of this Tower, the sea and the beaches with the idea that most people have of the city, and the perception of the Maria Pita and Pontevedra Square as the heart of the city and the most important node, respectively. The city has been described by many participants as "a small town with all amenities nearby."

Keywords: Public image, city, inhabitants, questionnaire.
\end{abstract}

El término “mapa cognitivo” fue utilizado por primera vez por Tolman (1948), para explicar los procesos de aprendizaje de laberintos en las ratas, asumiendo que había algo parecido a un mapa de rutas que guiaba la conducta del organismo en su medio. Sin embargo, fue el arquitecto Kevin Lynch (1960/2013) el que popularizó el concepto de mapa cognitivo de la ciudad entre los investigadores de diversas disciplinas, interesados en el estudio de la representación espacial ambiental y sus implicaciones (urbanistas, arquitectos, psicólogos, planificadores, geógrafos, etc.) (Carreiras, 1992).

Lynch destacó la importancia de un escenario físico capaz de generar una imagen clara ("legible”) que actúe como organizador y marco de referencia. Una ciudad legible, según Lynch, sería aquella cuyos elementos (distritos, sendas, lugares sobresalientes...) se pueden identificar y organizar fácilmente en una pauta global. Este arquitecto analizó las zonas centrales de tres ciudades de Estados Unidos (Boston, Nueva Jersey y Los Ángeles), llevando a cabo entrevistas con sus habitantes, y clasificó los contenidos de las imágenes de la ciudad en cinco tipos de elementos: Sendas, bordes, barrios, nodos e hitos.

Sendas son las calles, senderos, vías férreas, los conductos que conectan distintas partes de la ciudad, y que para muchos individuos son los elementos preponderantes en su imagen. Bordes son elementos lineales, referencias laterales que, en principio, el individuo no utiliza. Ejemplos de bordes son los muros, las playas, cruces de ferrocarril, murallas, etc. Distritos o barrios son secciones de la ciudad que son reconocibles como si tuvieran un carácter común que los identifica. Nodos son puntos estratégicos de la ciudad en los que el individuo puede entrar. Pueden ser cruces importantes de calles, plazas, o esquinas donde se reúne la gente. Por último, los hitos (o mojones) son, por lo general, objetos físicos definidos, como un edificio, una montaña, una señal, una torre, etc. Pueden estar dentro de la ciudad, siendo fundamentalmente locales, o a distancia, viéndose desde diversos ángulos.

Estos elementos no se podrían considerar de forma aislada, ya que, por ejemplo, los barrios están estructurados a partir de nodos, definidos por bordes, y pueden contar con sendas e hitos. A su vez, la imagen de un elemento puede cambiar en función de la perspectiva del observador. Por ejemplo, una autopista puede ser una senda para un conductor y un borde para un peatón. Por otro lado, el que resulten preponderantes unos elementos u otros depende de la ciudad de la que se trate (Lynch (1960/2013).

Lynch planteó que parece haber una imagen pública de cada ciudad, resultado de la superposición de muchas imágenes individuales, o una serie de imágenes públicas mantenidas por un número considerable de habitantes.

Desde su utilización por Lynch, las encuestas y los dibujos han sido las técnicas más utilizadas para el estudio de la imagen cognitiva de la ciudad. Pedir a los individuos que dibujen un mapa de su ciudad o de su barrio es una técnica muy sencilla y fácil de aplicar, con la que se puede obtener información diversa, fundamentalmente sobre las cuestiones y elementos analizados por Lynch, aunque las imprecisiones que se observen en los dibujos puedan deberse más a la falta de habilidad en el manejo del dibujo que a una representación espacial imprecisa (De Vega, 1984; Lázaro Ruíz, 2000).

Las encuestas han sido también muy utilizadas por arquitectos, psicólogos, geógrafos y profesionales de otros ámbitos. Ya se ha indicado que la información 
obtenida a través de esta técnica puede ser utilizada en el diseño y planificación de las ciudades para facilitar la orientación y el desplazamiento de sus habitantes. También los geógrafos emplean encuestas y dibujos para llevar a cabo estudios descriptivos sobre las ciudades. Se han publicado algunos trabajos llevados a cabo con estas técnicas, por especialistas de esta disciplina, sobre varias ciudades españolas: la ciudad de Valencia (Boira, 1992), la ciudad de Segovia (García Ballesteros y Bosque Sendra, 1989), o la ciudad alicantina de Petrer (Ponce, Dávila, y Navalón, 1994), son algunos ejemplos.

Los psicólogos han empleado también estos métodos para conocer los elementos de la imagen de la ciudad y las opiniones y percepciones de los habitantes sobre diversos aspectos. Fernández González estudió cómo influyen variables como la edad, la familiaridad con la ciudad, y el género en la representación de la ciudad de Ourense (Fernández González, 2005; 2014). García Mira (1997) llevó a cabo un estudio sobre la evaluación de la calidad ambiental de los barrios de la ciudad de A Coruña y sobre la satisfacción de sus habitantes.

Con este estudio se deseaba averiguar cómo es la imagen que los alumnos de la Facultad de Ciencias de la Educación de la Universidad de A Coruña tienen de esta ciudad, utilizando para ello la encuesta como técnica.

\section{Método}

\section{Participantes}

En este estudio participó un grupo de 130 estudiantes del primer curso de los Grados de Educación Social y Logopedia de la Facultad de Ciencias de la Educación de A Coruña, 32 hombres y 98 mujeres, con una media de edad de 19.92 años $(S D=2.49)$.

\section{Material}

Se utilizó el cuestionario utilizado por Boira (1992), con algunas modificaciones.

\section{Procedimiento}

Al alumnado de primer curso de los grados de Educación Social y de Logopedia, en sus respectivas clases, se les entregó el cuestionario para que lo cumplimentaran, sin límite de tiempo. Posteriormente, se codificaron las respuestas a los diferentes ítems. De todas las preguntas del cuestionario, en su mayoría preguntas abiertas, para este estudio se analizó la información referida a la evaluación global de la ciudad, los lugares considerados más céntricos y representativos, las preferencias residenciales, lo que los habitantes perciben como lo mejor y peor de la ciudad, y los conceptos que más asocian con la ciudad. Esta información corresponde con los ítems 1, 2, 3, 6, 7, 9, 10, 11 y 15 del cuestionario modificado, al igual que en el cuestionario de Boira (1992).

\section{Resultados}

Deseábamos conocer la imagen de la ciudad de A Coruña que tenía el alumnado de primer curso de los grados de Educación Social y Logopedia de esta ciudad. Para ello, a partir de la codificación de las respuestas de los participantes, se investigó el porcentaje de citas recibidas por los lugares señalados, en los ítems de la escala que interesaban para este estudio.

La primera información que se obtuvo fue la relacionada con la evaluación global que los encuestados hacían de la ciudad, en respuesta al primer ítem: “¿Cuánto diría que le gusta la ciudad de A Coruña?“. Los porcentajes obtenidos en las diferentes posibilidades de respuesta que ofrecía este ítem, se encuentran en la Figura 1.

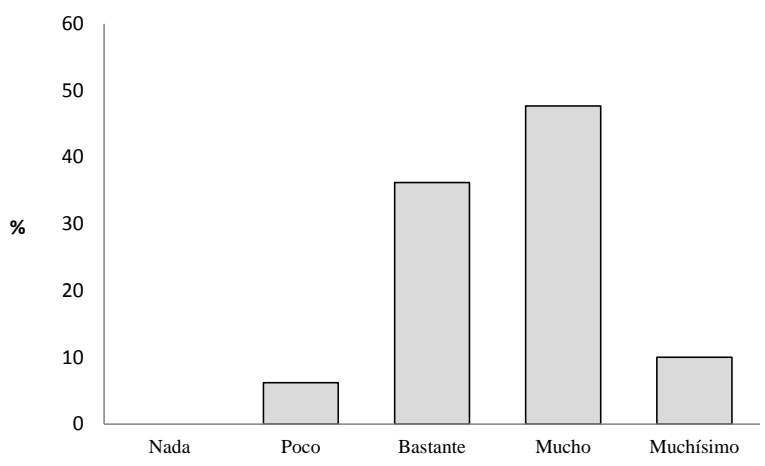

Figura 1. Evaluación global de la ciudad. Respuestas a la pregunta ¿Cuánto diría que le gusta la ciudad de A Coruña?

La mayoría de los participantes valora la ciudad de forma positiva. Un 36.2\% asegura que la ciudad le gusta bastante, y un $57.7 \%$ de los participantes asegura que le gusta "mucho" o "muchísimo" (47.7\% y 10\%, respectivamente), frente a un escaso $6.2 \%$ de participantes que afirma que la ciudad le gusta "poco". Ningún participante ha seleccionado "nada” como respuesta a esta pregunta.

A continuación, a los estudiantes se les pedía que enumerasen los cinco lugares de la ciudad de A Coruña que espontáneamente les vinieran a la mente. Los resultados de esta pregunta abierta, ordenados por porcentaje de recuerdo, se encuentran en la Tabla 1.

Tabla 1.

Lugares de la ciudad de A Coruña recordados espontáneamente con mayor frecuencia (Ordenados de mayor a menor por porcentaje de veces que han sido citados)

\begin{tabular}{clc}
\hline Orden & Nombre del lugar & Porcentaje \\
\hline 1 & Torre de Hércules & 68.46 \\
2 & Playa de Riazor / Orzán & 49.23 \\
3 & Monte de San Pedro & 39.23 \\
4 & Calle Real & 26.92 \\
5 & Plaza de María Pita & 23.85 \\
\hline
\end{tabular}

En esta pregunta abierta, la mayoría de individuos recordaron espontáneamente la Torre de Hércules (68.46\%), a la que siguieron en porcentaje de citas las playas de Riazor y Orzán, citadas por el $49.23 \%$ de los participantes. Los otros tres lugares citados con más frecuencia han sido, por este orden, el Monte de San Pedro (39.23\%), la Calle Real (26.92\%) y la Plaza de María Pita (23.85\%). 
A continuación, en la Tabla 2, se muestran las respuestas de los encuestados al ítem 3 del cuestionario: "Piense en las diferentes zonas y barrios dela ciudad de A Coruña. ¿Dónde le gustaría vivir si fuera enteramente libre de elegir?”. En las respuestas a este ítem se ha encontrado bastante dispersión. Esto explica que en la tabla que aparece a continuación, los porcentajes para los cinco lugares más citados no son muy elevados, aunque son los más altos para la pregunta evaluada .

Tabla 2.

Zona o barrio de la ciudad de A Coruña elegida para vivir (Ordenados de mayor a menor por porcentaje de veces que han sido citados)

\begin{tabular}{clc}
\hline Orden & Nombre del lugar & Porcentaje \\
\hline 1 & Playa de Riazor / Orzán & 20.49 \\
2 & Plaza de Pontevedra & 13.93 \\
3 & Ciudad Vieja & 7.38 \\
4 & Monte Alto & 7.38 \\
5 & C.Jardin/P.Marítimo/R.Outeiro & 4.92 \\
\hline
\end{tabular}

La cercanía a las playas de Riazor y Orzán ha sido la respuesta que más participantes han ofrecido (el 20.49\%), quedando en segundo lugar la Plaza de Pontevedra (13.93\%). La Ciudad vieja y el Barrio de Monte Alto han recibido un $7.38 \%$ de citas, mientras que tanto Ciudad Jardín como el Paseo Marítimo y la Ronda de Outeiro han aparecido citadas por un porcentaje de participantes inferior al 5\% .

A los participantes se les pidió que indicaran las tres cosas que considerasen mejores y peores de la ciudad de A Coruña. En la Figura 2 aparecen las tres que, en función de las citas recibidas, serían las mejor consideradas por los participantes.

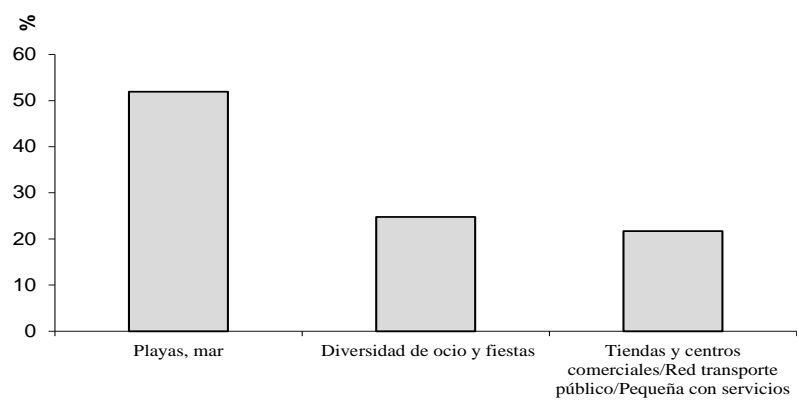

Figura 2. Aspectos destacados por los encuestados como las “cosas mejores” de la ciudad de A Coruña.

Las playas (o la cercanía al mar) ha sido lo que un porcentaje mayor de estudiantes ha destacado como lo más positivo, con un $67 \%$ de citas, seguido de la diversidad en la oferta de ocio y fiestas (con un 32\%). El tercer porcentaje de respuestas en este ítem corresponde a más de un elemento, todos ellos agrupados en la misma columna en la figura por haber obtenido los tres un $28 \%$ de citas (la red de transporte público urbano, los centros comerciales, y el hecho de que la ciudad sea, tal como muchos participantes han definido, "una ciudad pequeña con todos los servicios cerca”).
A continuación, en la Figura 3, se refleja lo que ha sido señalado con los tres mayores porcentajes de citas como lo peor de la ciudad.

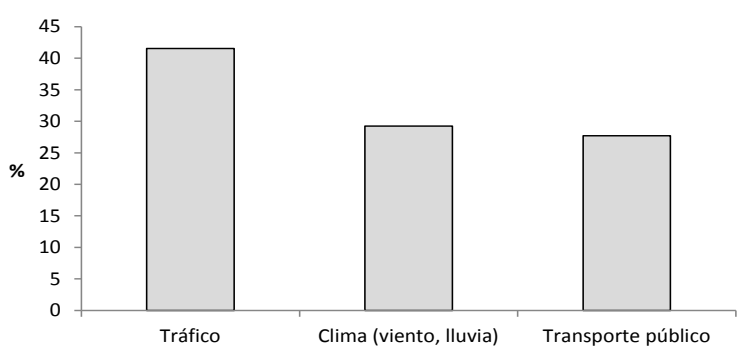

Figura 3. Aspectos destacados por los encuestados como las “cosas peores” de la ciudad de A Coruña.

Los aspectos de la ciudad que los habitantes encuestados perciben como más negativos son, por este orden: el tráfico (54\%), el clima (38\%), y algunos aspectos concretos del transporte público (36\%).

Se les planteó también a los participantes lo siguiente: "Señale, por favor, las dos palabras que, para usted, mejor se relacionan con la idea de "ciudad de A Coruña”. Sus respuestas a este ítem se reflejan en la Figura 4.

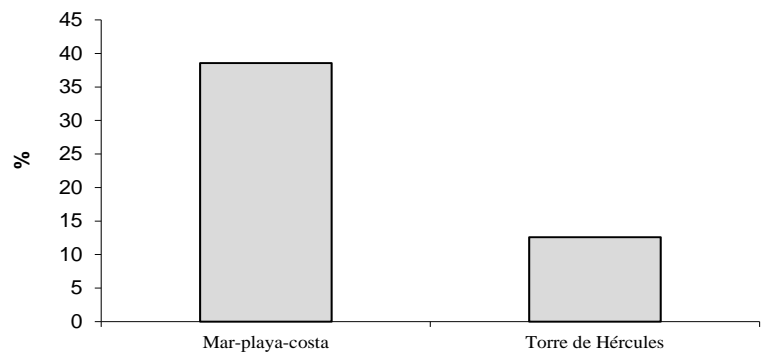

Figura 4. Conceptos con mayor asociación con la idea de "ciudad de A Coruña”.

Los conceptos que más estudiantes asocian con la ciudad de A Coruña son, por un parte, el mar, las playas, la costa (un $38.58 \%$ ), que se han agrupado como una única referencia, y, por otro lado, la Torre de Hércules (12.6\%).

En la Tabla 3 aparecen las cinco calles o plazas más importantes de la ciudad, en función del número de veces que han sido citadas como respuesta al ítem 9: ¿Cuáles son las cinco calles o plazas más importantes de la ciudad de A Coruña?

Tabla 3.

Calles o plazas más importantes de la ciudad (Ordenados de mayor a menor por porcentaje de veces que han sido citados)

\begin{tabular}{ccc}
\hline Orden & Nombre del lugar & Porcentaje \\
\hline 1 & Plaza de Pontevedra & 81.54 \\
2 & Plaza de María Pita & 66.92 \\
3 & Calle Real & 60.00 \\
4 & Plaza de Lugo & 36.15 \\
5 & Cuatro Caminos & 20.00 \\
\hline
\end{tabular}

La Plaza de Pontevedra aparece citada como la plaza más importante de la ciudad por un porcentaje muy 
elevado de encuestados, el 81.54\%. Porcentajes también altos, y similares entre sí, los han obtenido la Plaza de María Pita (66.92\%) y la Calle Real (60\%). Con bastantes menos citas en esta clasificación de calles o plazas más importante de la ciudad, están otros dos lugares, la Plaza de Lugo y Cuatro Caminos, con un $36.15 \%$ y un $20 \%$ de citas, respectivamente.

En la Tabla 4 se muestran los cinco lugares que han sido señalados en otra pregunta abierta como los principales puntos de reunión o encuentro de los residentes de la ciudad.

Tabla 4.

Principales puntos de reunión o encuentro de los residentes de la ciudad (Ordenados de mayor a menor por porcentaje de veces que han sido citados)

\begin{tabular}{clc}
\hline Orden & Nombre del lugar & Porcentaje \\
\hline 1 & Plaza de Pontevedra & 56.92 \\
2 & Jardines de Méndez Núñez & 42.31 \\
3 & Obelisco & 37.69 \\
4 & Marineda City & 35.38 \\
5 & C/ Real & 34.62 \\
\hline
\end{tabular}

Se ha encontrado que la plaza de Pontevedra es el lugar que más participantes han señalado también como principal punto de reunión o encuentro de los residentes de la ciudad (56.92\%). Los otros cuatro lugares más señalados, por orden de porcentaje de citas, han sido: los Jardines de Méndez Núñez (42.31\%), el Obelisco (37.69\%), el centro comercial Marineda City (35.38\%), y la Calle Real (34.62\%).

Para saber qué lugares consideran los participantes del estudio como lo más representativo de la ciudad, se les preguntó por los cinco lugares o cosas de la ciudad de A Coruña que señalarían a un extranjero que la visitara por primera vez. En la Tabla 5 se presentan los lugares más citados como respuesta a esta cuestión.

Tabla 5.

Lugares o cosas de la ciudad que señalarían a quien la visitara por primera vez (Ordenados de mayor a menor por porcentaje de veces que han sido citados)

\begin{tabular}{ccc}
\hline Orden & Nombre del lugar & Porcentaje \\
\hline 1 & Torre de Hércules & 92.31 \\
2 & Monte de San Pedro & 52.31 \\
3 & Playas de Riazor / Orzán & 35.38 \\
4 & Casa de los peces & 33.08 \\
5 & Plaza de María Pita & 28.46 \\
\hline
\end{tabular}

Prácticamente la totalidad de los encuestados señalan a la Torre de Hércules como lo primero que enseñarían a alguien que visitara la ciudad por primera vez (el $92,31 \%)$, con bastante diferencia -en porcentaje de elecciones- de los siguientes lugares señalados, que son, por este orden y con sus correspondientes porcentajes, el Monte de San Pedro (52,31\%), las playas (35,38\%), la Casa de los Peces $(33,38 \%)$ y la Plaza de María Pita (28.46\%).

En el último ítem analizado en este estudio se preguntaba: “¿Dónde tiene usted la impresión de hallarse en pleno corazón de la ciudad de A Coruña? (pregunta cerrada; alternativas de respuesta: En la Plaza de Azcárraga, en la Plaza de María Pita, en la Plaza de
Pontevedra, en otro lugar)”. Las respuestas aparecen en la Figura 5.

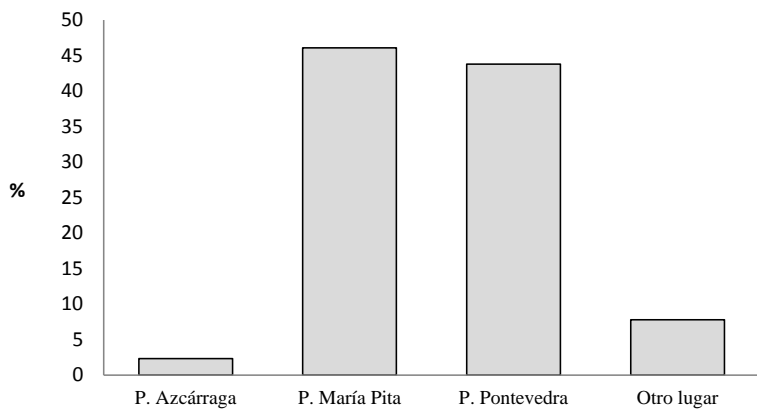

Figura 5. Lugar destacado por los encuestados como “Corazón de la ciudad” de A Coruña.

De las cuatro alternativas de respuesta ofrecidas, la mayoría de los estudiantes ha seleccionado como corazón de la ciudad la Plaza de María Pita (el 46.1\%) y, en segundo lugar, pero con escasa diferencia, la Plaza de Pontevedra, citada por el $43.8 \%$ de participantes. Sólo un 2.3\% de los estudiantes ha seleccionado la Plaza de Azcárraga, mientras que el $7.8 \%$ considera que el corazón de la ciudad no es ninguno de los tres lugares ofrecidos, seleccionando como respuesta a este ítem "otro lugar".

\section{Discusión}

Entre los elementos citados con más frecuencia en las preguntas del cuestionario utilizadas en este estudio, podemos encontrar, en mayor o menor medida, todos los elementos señalados por Lynch, lo que según este autor permitiría hablar de la legibilidad de la ciudad. Los resultados confirman el papel central de la Torre de Hércules en la imagen de la ciudad como elemento simbólico y representativo, típicamente un hito destacado según la clasificación de Lynch. Prácticamente la totalidad de los encuestados la señalan como lo primero que enseñarían a alguien que visitara la ciudad por primera vez (el 92,31\%). Es también el primer lugar recordado espontáneamente con más frecuencia, y uno de los dos nombres que, en una pregunta abierta, más habitantes han asociado con la idea de "ciudad de A Coruña” (además de la palabra “Mar” -mar, playa o costa-).

Las respuestas a las tres cuestiones anteriores (lugares de la ciudad recordados espontáneamente, lugares que habría que enseñar a alguien que no conociera la ciudad, y conceptos más asociados con la idea de esta ciudad) resultan especialmente reveladoras sobre cuáles son los elementos más significativos en la imagen de la ciudad. Los participantes contestan a estas preguntas sin ser orientados hacia ninguna categoría en particular, algo que sí ocurre en otros ítems del cuestionario, que preguntan directamente al encuestado por algún elemento concreto (plazas y calles, por ejemplo).

El lugar percibido como "corazón de la ciudad” por un porcentaje más elevado de individuos es la Plaza de María Pita, que puede considerarse nodo e hito a un 
tiempo, sobre todo por la asociación de la plaza con el edificio del ayuntamiento, ubicado en ella. En esta clasificación del centro subjetivo de la ciudad, le sigue con un porcentaje muy cercano otro nodo, la Plaza de Pontevedra, que también aparece seleccionada como la plaza más importante de la ciudad, y es uno de los lugares que más personas elegirían para vivir (tras las playas de Riazor y Orzán).

Lo más valorado de la ciudad son el mar y las playas, seguido de la diversidad en la oferta de ocio y fiestas y, con el mismo porcentaje de elecciones, la red de transporte público urbano, los centros comerciales, y el hecho de que la ciudad sea, tal como muchos participantes han coincidido en definir (a pesar de que era una pregunta abierta) como "una ciudad pequeña con todos los servicios cerca”. Estos aspectos aparecen también en otros estudios de este tipo. El ambiente, las fiestas, la playa, el mar, y el tamaño de la ciudad, se encuentran entre los elementos más destacados en el estudio de Boira (1992) sobre Valencia, otra ciudad costera española. También la importancia dada por los jóvenes a los centros comerciales ha sido destacada en otros estudios (Bernal Santa Olalla, 2003). Es habitual que los autores, conscientes de la importancia que la actividad comercial y de servicios tiene para los habitantes de la ciudad en general, incluyan en sus entrevistas preguntas de valoración de esta cuestión (Garcia Mira, 1997; Ponce, Dávila y Navalón, 1994).

Los aspectos de la ciudad que los habitantes encuestados perciben como más negativos son, por este orden: el tráfico, el clima (referencias frecuentes al viento y a la lluvia), y algunos aspectos concretos del transporte público. El tráfico, que era ya uno de los temas preponderante en las entrevistas que realizó Lynch hace décadas (Lynch, 1960/2013), es una queja frecuente en otros ciudades, y aparece citado también como lo más negativo en el estudio de Boira (1992).

Por lo que respecta a la impresión global de la ciudad, la puntuación media obtenida es de 3.6 (sobre 5). Un $36.2 \%$ asegura que la ciudad le gusta bastante, y un $57.7 \%$ de los participantes asegura gustarle "mucho" o "muchísimo", frente a un escaso 6.2\% que asegura gustarle "poco". Puesto que la mayoría de los encuestados la valoran favorablemente, puede concluirse que la percepción dominante de la ciudad es positiva.

\section{Referencias}

Bernal Santa Olalla, B. (2003). Los jóvenes y la ciudad. Análisis y valoración del patrimonio urbano en quince ciudades históricas. En L. López, C. E. Relea, y J. Somoza (Coord.), La ciudad. Nuevos procesos, nuevas respuestas (pp. 373-387). León: Universidad de León.

Boira, J. V. (1992). La ciudad de Valencia y su imagen pública. Valencia: Universidad de Valencia.

Carreiras, M. (1992). Mapas cognitivos y orientación espacial. En J. Mayor y J L. Pinillos (Eds.), Tratado de psicología general (Vol. 4): Memoria y representación (pp. 375-408). Madrid: Alhambra Universidad.

De Vega, M. (1984). Introducción a la psicología cognitiva. Madrid: Alianza.

Fernández González, A. (2005). The Influence of developmental maturity in the environmental representation of the city: An empirical approach. En R. García-Mira, D. L. Uzell, J. E. Real y J. Romay (Eds.), Housing, space and quality of life (pp. 139-150). Aldershot, UK: Ashgate.

Fernández González, A. (2014). Cognición ambiental de la ciudad: Una aproximación al caso de Ourense. Tesis Doctoral no publicada. Universidade de Santiago de Compostela.

García Ballesteros, A., y Bosque Sendra, J. (1989). El espacio subjetivo de Segovia. Madrid: Editorial Universidad Complutense.

García Mira, R. (1997). La ciudad percibida. Una psicología ambiental de los barrios de A Coruña. A Coruña: Servicio de Publicaciones de la Universidad de A Coruña.

Lázaro Ruiz, V. (2000). La representación mental del espacio a lo largo de la vida. Zaragoza: Egido Editorial.

Lynch, K. (1960). The image of the city. Cambridge, MA: MIT Press. [Trad. Cast. (2013). La imagen de la ciudad. Barcelona: Gustavo Gili].

Ponce, G., Dávila, J. M., y Navalón, M. R. (1994). Análisis urbano de Petrer. Estructura urbana y ciudad percibida. Alicante: Universidad de Alicante.

Tolman, E. C. (1948). Cognitive maps in rats and men. Psychological Review, 55, 189-208. 